\title{
Serum IgG Autoantibodies Directed against the $\alpha$ Chain of FceRl: A Selective Marker and Pathogenetic Factor for a Distinct Subset of Chronic Urticaria Patients?
}

\author{
Edda Fiebiger, ${ }^{*}$ Dieter Maurer, ${ }^{*}$ Henriette Holub, ${ }^{*}$ Bärbel Reininger, ${ }^{\star}$ Gabriella Hartmann, ${ }^{\ddagger}$ Max Woisetschläger, ${ }^{\ddagger}$ \\ Jean-Pierre Kinet, ${ }^{\$}$ and Georg Stingl* \\ * Department of Dermatology, Division of Immunology, Allergy and Infectious Diseases, University of Vienna Medical School, A-1090 \\ Vienna, Austria; ${ }^{\ddagger}$ Sandoz Research Institute, A-1230 Vienna, Austria; and ${ }^{\S}$ Molecular Allergy and Immunology Section, National \\ Institute of Allergy and Infectious Diseases, National Institutes of Health, Rockville, Maryland 20892
}

\begin{abstract}
While it is well established that acute allergic urticaria is caused by degranulation of skin mast cells occurring after allergen/IgE-dependent cross-linking of high affinity IgE receptors (Fce RI), the pathophysiologic mechanisms operative in chronic urticaria $(\mathrm{CU})$ are less well understood. Some evidence points to the existence of histamine-releasing activity in the serum of $\mathrm{CU}$ patients which possibly acts via triggering of FceRI. In this study, we aimed to better characterize this anti-Fce $R I \alpha$ reactivity of $C U$ patients using affinity-purified, IgE-depleted IgG fractions of such individuals (CU-IgG). Using immobilized, recombinant soluble FceRI $\alpha$ as a reaction target for Western blot studies, we found that $12 / 32(37 \%)$ CU-IgG serum samples exhibited IgG autoreactivity against Fce RI $\alpha$. These findings were confirmed by experiments demonstrating that immunoblot-reactive, but not immunoblot-nonreactive, $\mathrm{CU}$-IgG preparations precipitated the FceRI $\alpha$ from FceRI $\gamma \gamma$-transfected cells. No anti-Fce $R I \alpha$ reactivity was observed in IgG fractions from atopic dermatitis (AD) patients $(0 / 15)$ or healthy control individuals (CO: 0/15). As opposed to the selective occurrence of IgG anti-Fce RI $\alpha$ autoantibodies in $\mathrm{CU}$ patients, IgG anti-IgE antibodies were detected in all groups investigated (CU: 69\%; AD: 73\%; CO: 26\%). While both types of autoantibodies can exhibit histamine-releasing properties, not all of the autoantibodies proved to be functional in vitro. Our results indicate that the occurrence of IgG anti-Fce $\operatorname{RI} \alpha$ reactivity defines an autoimmune-mediated subentity of $\mathrm{CU}$ and provide a basis for the development of new diagnostic procedures and, perhaps, therapeutic strategies for this disease. (J. Clin. Invest. 1995. 96:26062612.) Key words: autoimmunity $\bullet$ IgE receptors $\bullet$ histamine release - mast cell degranulation • pseudoallergic reaction
\end{abstract}

Address correspondence to Edda Fiebiger, B.A., Department of Dermatology, Division of Immunology, Allergy and Infectious Diseases (DIAID), University of Vienna Medical School, Währinger Gürtel 18-20, A-1090 Vienna, Austria. Phone: 1-4036933; FAX: 1-4031900.

Received for publication 14 March 1995 and accepted in revised form 3 August 1995.

1. Abbreviations used in this paper: AD, atopic dermatitis; BSA-NP, nitrophenylacetyl-coupled BSA; CHO, Chinese hamster ovary cells; $\mathrm{CO}$, healthy control individuals; $\mathrm{CU}$, chronic urticaria; FceRI, high affinity receptor for the Fc part of IgE; Fc $\gamma$ Rs, receptors for the Fc part of IgG; MC, mast cell.

The Journal of Clinical Investigation, Inc.

Volume 96, December 1995, 2606-2612

\section{Introduction}

Chronic urticaria $(\mathrm{CU})^{1}$ is a common disorder characterized by the eruption of transitory, itchy skin swellings which recur for weeks to years. Several conditions such as bacterial or fungal infections, psychological factors, neoplasms, and intolerance to certain food additives $(1,2)$ have been found in connection with CU symptoms and, thus, were implicated as etiopathogenetic factors. However, in a given patient, the tedious and laborious search for such conditions is usually not revealing and, even if successful and appropriately dealt with, not necessarily followed by the resolution of symptoms (1).

Since urticaria is the consequence of vasoactive mediator release from skin mast cells (MC) (3), intensive research has focused on the nature of histamine-releasing factors in CU. These studies accumulated evidence for the presence of MCactivating factors within the immunoglobulin ( $\mathrm{Ig}$ ) and/or nonimmunoglobulin (e.g., substance $P$ and lipid-derived mediators) fraction of CU serum (2). Classical Ig-mediated type I allergic reactions, i.e., allergen-induced cross-linking of $\operatorname{IgE}$ bound to its high affinity receptor (FceRI) on skin MC $(4,5)$, are apparently not a common cause for the observed Ig-mediated histamine-releasing activity in CU since allergen-specific IgE can only rarely be identified and total IgE levels are usually normal in CU sera. Evidence for the pathogenetic importance of Ig isotypes other than IgE came from the observation that severe $\mathrm{CU}$ episodes can be ameliorated or even abolished after IgG adsorbance by plasmapheresis (6). In fact, serum IgG antiIgE autoantibodies with MC-activating properties have been described in $\mathrm{CU}(7,8)$. Further evidence for a role of $\mathrm{IgG}$ autoantibodies in $\mathrm{CU}$ came from a recent study demonstrating histamine-releasing capacity of serum IgG isolates that could be blocked by soluble FceRI $\alpha$ chain (9). Therefore, it was reasoned that FceRI can be a target structure recognized by IgG autoantibodies (9). The experimental conditions chosen were not able to determine whether the observed FceRI-mediated MC degranulation was due to $(a)$ in vivo formed IgG/anti-IgE autoantibody complexes (10) which may copurify with the IgG fraction, and/or $(b)$ IgE-independent FceRI $\alpha$-specific IgG autoantibodies. To distinguish between these two possibilities, we investigated the antigen and epitope specificity of histaminereleasing autoantibodies in IgG fractions devoid of IgG/antiIgE complexes.

\section{Methods}

Patients and controls. 30 patients with CU, defined as recurrent wheals lasting $<24 \mathrm{~h}$ and occurring at least twice a week for over 2 mo, were recruited $(2,11)$. Patients with clinical evidence of urticarial vasculitis or physical urticaria were excluded. None of the patients were taking 
steroids or immunosuppressive drugs at the time of venipuncture. In addition, sera from 15 patients suffering from atopic dermatitis (AD) (12) were collected and sera from 15 healthy individuals (CO) served as controls. All sera were stored at $-20^{\circ} \mathrm{C}$ until investigation.

Isolation of $\mathrm{Ig} G$ fractions. IgG was purified from serum samples by affinity chromatography using protein $\mathrm{G}$ columns (Pierce, Rockford, IL) according to the manufacturer's instructions. Eluates containing IgG were adjusted to $10 \mathrm{mg} / \mathrm{ml}$ and analyzed for contaminating IgE by ELISA (Pharmacia Biotech, Brussels, Belgium). After running on a 5\% SDS-PAGE gel, purity of the IgG fraction was confirmed by protein staining (copper stain kit; Bio-Rad Laboratories, Richmond, CA) and by anti-IgG (Jackson ImmunoResearch Laboratories, Inc., West Grove, PA) or anti-IgE (Accurate Chemical \& Scientific Corp., Westbury, NY) Western blotting. To selectively denature IgE molecules possibly contaminating the protein $\mathrm{G}$ eluates, fractions were heated for $3 \mathrm{~h}$ at $56^{\circ} \mathrm{C}$ as described $(13,14)$.

Immunoaffinity depletion of IgE. Immunoaffinity-purified, polyclonal goat anti-human IgE (Chemicon International, Inc., Temecula, CA) was immobilized on $\mathrm{CH}$ Sepharose $4 \mathrm{~B}$ (Pharmacia) according to the manufacturer's guidelines. Depletion of a myeloma IgE sample ( 500 $\mu \mathrm{g} / \mathrm{ml}$ ) was used to establish the IgE-binding capacity of the anti-IgE column. IgE depletion was performed by passing IgG specimens through the affinity column twice.

$m A b s$ used in the study. The anti-FceRI $\alpha$ mAbs 15-1 and 19-1 were described recently (15). Chimeric human IgE anti-nitrophenylacetyl (NP; cIgE) and myeloma IgE were purchased from Serotec Ltd. (Oxford, United Kingdom). IgG1 and IgG2a isotype controls were obtained from Sigma Chemical Co. (St. Louis, MO).

Cell lines. Chinese hamster ovary (CHO) cells were obtained from the American Type Culture Collection (Rockville, MD). Stable transfectants coexpressing the human FceRI $\alpha$ - and FceRI $\gamma$ chain ( $\mathrm{CHO} \alpha \gamma$ cells) have been described previously (15).

Human recombinant soluble FcERI $\alpha$. The gene segment encoding the extracellular portion of human FceRI $\alpha$ (16) was cloned into the baculovirus vector $\mathrm{pVL}$ 941. Recombinant baculovirus was generated in insect cells (Invitrogen, San Diego, CA) using the Baculogold transfection kit (PharMingen, San Diego, CA) according to the manufacturer's instructions. The soluble receptor molecule was purified from supernatants of infected insect cells by a two-step chromatography protocol. First, the material was immunoaffinity-purified on a Sepharose 4Bcoupled (Pharmacia Biotech, Uppsala, Sweden) mouse anti-human FceRI $\alpha$ mAb. Final purification was achieved by anion exchange column chromatography (Mono Q; Pharmacia Biotech). The purification product migrated as a single $32-\mathrm{kD}$ band as judged by silver staining of a denaturing polyacrylamide gel.

SDS-PAGE and immunoblotting. Soluble recombinant FceRI $\alpha$ (200-400 ng/lane) or precipitated samples were submitted to electrophoresis on $10-13 \%$ gels and blotted onto nitrocellulose membranes (Bio-Rad Laboratories) which were then blocked with 5\% dry milk/ $0.05 \%$ Tween 20 (Sigma Chemical Co.)/PBS for at least $6 \mathrm{~h}$. Reactivities of FceRI $\alpha$-specific mAb 19-1 and the IgG2a isotype control mAb $(200 \mathrm{ng} / \mathrm{ml})$ were detected with a goat anti- mouse horseradish peroxidase conjugate $(1: 40,000)$ (Bio-Rad Laboratories). Binding of the biotinylated mAb 19-1 and the biotinylated isotype control mAb were detected using a streptavidin horseradish peroxidase conjugate $(1: 2,000)$ (Amersham International, Buckinghamshire, United Kingdom). For the detection of FceRI $\alpha$-reactive serum Abs, membranes were reacted with purified IgG specimens diluted 1:25 or 1:10 (i.e., 400 or $1,000 \mu \mathrm{g} \mathrm{IgG/}$ $\mathrm{ml}$ ). As controls, binding of native and heat-denatured myeloma IgE $(10 \mu \mathrm{g} / \mathrm{ml})$ to membrane-bound soluble Fc $\varepsilon \mathrm{RI} \alpha$ was investigated. Membrane-bound first-step antibodies were detected with either rabbit anti-human IgG $(1: 50,000)$ or rabbit anti-human IgE horseradish peroxidase conjugates $(1: 30,000)$. Membranes were incubated with ECL developing solution (Amersham International) and exposed to Kodak $\mathrm{X}$-Omat $\mathrm{S}$ films. For the detection of autoantibodies with anti-IgE properties the following procedure was used: $200-400 \mathrm{ng} /$ lane NP-conjugated BSA (BSA-NP) (17) were electrophoresed and blotted onto nitrocellulose membranes that were blocked with $5 \%$ dry milk/0.05\% Tween 20/PBS before exposure to $\operatorname{cIgE}(10 \mu \mathrm{g} / \mathrm{ml})$. The subsequent detection of membrane-bound IgG anti-IgE reactivity was performed as described above.

Immunoprecipitation. $\mathrm{CHO} \alpha \gamma$ cells were solubilized in $1 \% \mathrm{NP}-40$ Tris-lysis buffer as described (18). Before immunoprecipitation, lysates were precleared with protein $\mathrm{G}$ beads (Sigma Chemical Co.) for $4 \mathrm{~h}$. Lysates of $1 \times 10^{5}$ cells were incubated with $40 \mu$ lof the serum IgG specimens for $2 \mathrm{~h}$ at $4^{\circ} \mathrm{C}$. Next, protein $\mathrm{G}$ beads were added and samples were rotated for an additional hour at $4^{\circ} \mathrm{C}$. Precipitated proteins were eluted, electrophoresed, and immunoblotted with FceRI $\alpha$-specific mAb 19-1 as described above.

Biotinylation of IgG fractions. IgG fractions were dialyzed against buffer $\left(0.1 \mathrm{M} \mathrm{NaHCO}_{3}, 1 \mathrm{M} \mathrm{NaCl}\right)$ overnight and, thereafter, reacted with Biotin-X-NHS (Calbiochem-Novabiochem Co., La Jolla, CA) 15$30 \mathrm{mg} / \mathrm{ml} / \mathrm{mg}$ protein for $1 \mathrm{~h}$ at room temperature.

Flow cytometric studies. The binding of biotinylated Abs to FceRI $\alpha \gamma$-transfected and untransfected CHO cells was visualized by incubating the cells with $1 \mu \mathrm{g} / \mathrm{ml}$ streptavidin-PE (Becton Dickinson \& Co., Mountain View, CA). Cellular fluorescence was analyzed on a FACScan flow cytometer supported by Lysis II software (both from Becton Dickinson \& Co.). In the blocking studies, cells were incubated with $50 \mu \mathrm{g} / \mathrm{ml}$ of $\mathrm{mAb} 15-1, \mathrm{mAb} 19-1, \mathrm{mAb} 15-1$, and $\mathrm{mAb} 19-1$, or $20-200 \mu \mathrm{g} / \mathrm{ml} \mathrm{cIgE}$ before exposure to the biotinylated cIgE or serum IgG fractions.

Histamine release. Histamine release assays were performed with basophil-enriched peripheral blood cells from two unrelated healthy volunteers. Removal of in vivo bound IgE from basophils was performed after dextran sedimentation as described (19). Where indicated, basophils were reconstituted with $\operatorname{cIgE}\left(10 \mu \mathrm{g} / \mathrm{ml}, 30 \mathrm{~min}, 4^{\circ} \mathrm{C}\right)$. Basophilenriched cell fractions were incubated for $40 \mathrm{~min}$ at $37^{\circ} \mathrm{C}$ in buffer containing IL-3 (20) and 1:2, 1:5, 1:10, or 1:20 dilutions of serum IgG fractions from patients or healthy controls. Monoclonal anti-human IgE antibody was used as a positive control. Histamine release was measured with RIA (Immunotech International, Marseille, France) and expressed as a percentage of total cellular histamine. Spontaneous release accounted always for $<5 \%$ of total histamine.

\section{Results}

Protein $G$ isolates from serum of $C U$ patients react with recombinant FcERIa. In a first set of experiments we aimed to gain biochemical evidence for the occurrence of anti-FceRI $\alpha$ immunoreactivity in CU sera. Our test system uses recombinant FceRI $\alpha$ protein that has been expressed in baculovirus-infected insect cells as a truncated non-fusion protein lacking the transmembrane/intracytoplasmic domain. Westen blot experiments revealed that the soluble FceRI $\alpha$ is recognized by the FceRI $\alpha$ chain-specific mAb 19-1 as a single protein band of 30-35 $\mathrm{kD}$ and, to a lesser extent, as a dimer of $\sim 65 \mathrm{kD}$ (Fig. $1 \mathrm{~A}$, left panel) that disappears under reducing conditions (data not shown). The availability of this recombinant material as immunoblotted reaction target for serum antibodies enabled us to investigate large numbers of serum samples for the presence of the postulated anti-FceRI $\alpha$ immunoreactivity. Fig. $1 A$ depicts a representative immunoblot experiment showing that the protein G-binding fraction of a selected CU serum contains Fc $\varepsilon$ RI $\alpha$-binding activity that can be detected with anti-human IgG Abs. The antigenic specificity of the phenomenon was demonstrated by the inhibition of the binding of FceRI $\alpha$-specific moieties by incubation of CU-IgG fractions with soluble $\alpha$ protein before the reaction with the immunoblotted material (Fig. $1 A$ ). To definitively prove that FceRI $\alpha$ is recognized as a nondenatured protein by CU-IgG fractions, immunoprecipitation experiments using FceRI $\alpha \gamma$-transfected $\mathrm{CHO}$ cells were performed. Therefore, IgG fractions from $24 \mathrm{CU}$ patients were comparatively analyzed for their capacity to precipitate FceRI $\alpha$ from transfectants and to react with soluble FceRI $\alpha$ in Western 
A IMmUnoblotting

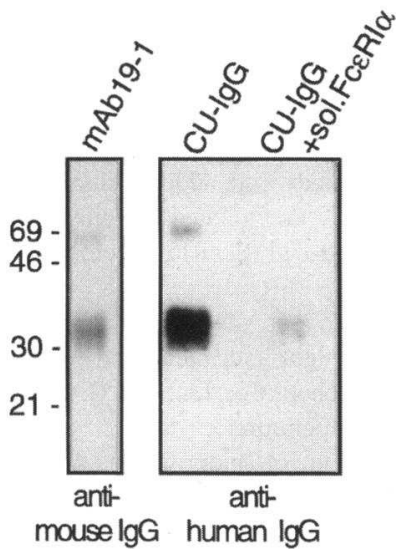

B

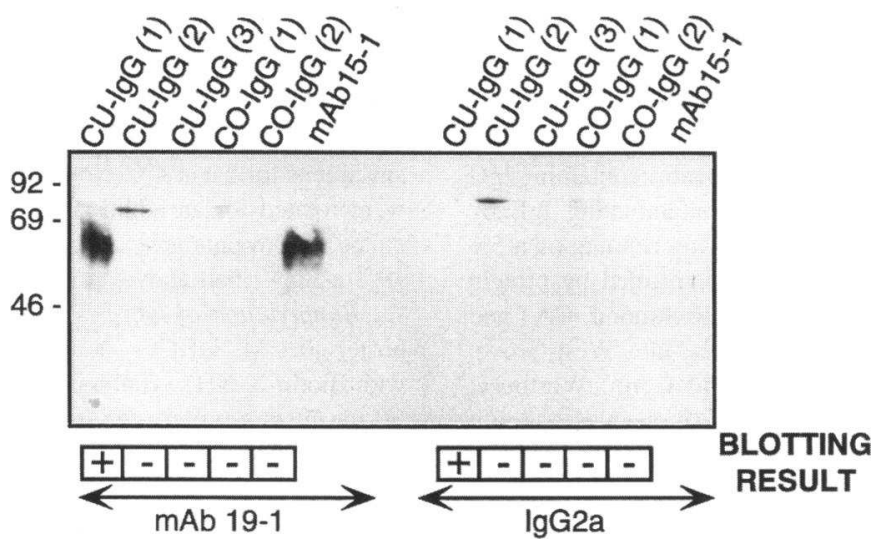

Figure 1. Serum IgG preparations of $\mathrm{CU}$ patients (CU-IgG) react with recombinant FceRI $\alpha$. (A) Recombinant FceRI $\alpha$ was electrophoresed and blotted onto nitrocellulose. Membranes were reacted with $\mathrm{Fc} \varepsilon \mathrm{RI} \alpha$-specific $\mathrm{mAb}$ 19-1 and CU-IgG in the presence or absence of excess soluble FceRI $\alpha$. Ab-binding was visualized with goat anti-mouse and rabbit anti-human IgG Abs, respectively. ( $B$ ) CU-IgG preparations [CU-IgG (1-3)], IgG specimens from healthy controls [CO$\operatorname{IgG}(1)$ and CO-IgG (2)], or the anti-Fc $\varepsilon$ RI $\alpha$ specific mAb 15-1 was reacted with lysates of

FceRI $\alpha \gamma$-transfected CHO cells. Precipitated proteins were blotted and reacted with biotinylated mAb 19-1 or a biotinylated IgG2a control mAb. Membrane-bound first-step mAbs were detected with streptavidin peroxidase. Molecular mass calibration is shown on the left in kilodaltons.

blot experiments. We found that the same 8/24 CU-IgG specimens that were reactive in immunoblot experiments precipitated FceRI $\alpha$ [50-70 kD (5)] from CHO $\alpha \gamma$ lysates [e.g., CU-IgG $(1)$; Fig. $1 B$ ]. No signals were obtained when either Western blot-nonreactive CU-IgG [(16/24), e.g., CU-IgG (2) and CUIgG (3); Fig. $1 B$ ], IgG from healthy controls [e.g., CO-IgG (1) and CO-IgG (2); Fig. $1 B$ ], or lysates from untransfected CHO cells (data not shown) were used for precipitation.

Since IgG anti-IgE serum antibodies would result in the copurification of IgE and IgG when applied to protein $\mathrm{G}$ columns, we had to determine whether the observed anti-FceRI $\alpha$ immunoreactivity derives from true IgG anti-FceRI $\alpha$ autoantibodies or, alternatively, may be due to the occurrence of IgG anti-IgE/IgE immune complexes. When we compared serum and protein $\mathrm{G}$ fractions for IgG- and IgE-mediated Ig-binding to immobilized FceRI $\alpha$ we found that unfractionated CU sera exhibited not only IgG but also IgE reactivity to the FceRI $\alpha$ protein whereas no IgE-binding was detectable with protein G-purified IgG fractions (Fig. 2, Exp. I). Since the remote possibility still existed that minute quantities of IgE had mediated IgG (anti-IgE)-binding to FceRI $\alpha$ molecules, protein $\mathrm{G}-$ IgG fractions were further subjected to selective heat denaturation of IgE and/or anti-IgE immunoaffinity depletion. To see whether these treatment modalities or the combination thereof are/is effective in prevention of IgE-binding to immunoblotted FceRI $\alpha$, their efficacy was tested on purified myeloma IgE. As demonstrated in Fig. 2, Exp. II, heat denaturation clearly reduces IgE-binding to FceRI $\alpha$ but does not influence the antiFc $\varepsilon$ RI $\alpha$ reactivity of CU-IgG fractions. The occurrence of FceRI $\alpha$-bound myeloma IgE was completely abrogated by selective heat denaturation of the protein $G$ fraction combined with two rounds of anti-IgE immunoaffinity depletion. In contrast to this loss of myeloma IgE-mediated immunoreactivity, CU-IgG-mediated anti-Fc $\varepsilon$ RI $\alpha$ reactivity remained unchanged under identical treatment conditions (Fig. 2, Exp. III). Taken together, these experiments demonstrate that the serum of certain $\mathrm{CU}$ patients contains IgG autoantibodies which recognize the IgE-binding a chain of FceRI in an IgE-independent manner.

FcERIa-specific IgG autoantibodies recognize epitopes closely related to the IgE-binding site of the high affinity receptor for IgE. Next, we investigated whether serum IgG from CU patients can bind to native FceRI $\alpha$ protein expressed on cell surfaces. As shown in Fig. $3 \mathrm{~A}$, heat-denatured and IgE-depleted $\mathrm{CU}-\mathrm{IgG}$ was found to bind to FceRI $\alpha \gamma$-transfected, but not untransfected, $\mathrm{CHO}$ cells, indicating that under native conditions the extracellular part of FceRI $\alpha$ is a specific target for serum autoantibodies in CU. The question of whether these IgG autoantibodies recognize epitopes related or unrelated to the IgE-binding site of the high affinity IgE receptor was addressed by blocking studies using anti-FceRI $\alpha$-reactive mAbs recognizing epitopes related to the IgE-binding site of FceRI $\alpha$ ( $\mathrm{mAb}$ 15-1 and mAb 19-1) or cIgE. Fig. $3 B$ shows that the binding abilities of biotinylated CU-IgG were modified by preincubation with either mAb 15-1 or mAb 19-1. Control experiments demonstrated that IgE-binding to FceRI $\alpha \gamma$-transfected CHO cells can be prevented by preincubation of the cells with mAb 15-1 or cIgE, but, possibly due to the low binding affinity of mAb 19-1 (Kinet, J.-P., unpublished observation), is hardly inhibited by this mAb. Nevertheless, the combination of mAb 15-1 and mAb 19-1 resulted in additive and, therefore, almost complete inhibition of CU-IgG-binding to FceRI $\alpha$ (Fig. 3 B). A virtually identical inhibitory effect on autoantibody-binding was observed when the FceRI $\alpha \gamma$-transfected cells had been preincubated with cIgE (Fig. $3 \mathrm{~B}$ ). These findings strongly suggest that the anti-FceRI $\alpha$ autoreactivity present in CU sera is directed against IgE-binding epitopes and/or epitopes closely related to the IgE-binding site of FceRI $\alpha$. Surprisingly, high concentrations $(200 \mu \mathrm{g} / \mathrm{ml})$ of cIgE were needed to completely prevent IgG autoantibody-binding to the transfectants (Fig. $3 B$ ). Preincubation of the cells with $20 \mu \mathrm{g} / \mathrm{ml} \mathrm{cIgE}$ was largely ineffective (data not shown). Taken together these data imply that FceRI $\alpha$ autoantibodies are present in considerably high concentrations and/or are affinity-matured, high affinity Abs as suggested by their IgG nature.

Serum IgG specimens from CU patients contain IgG autoreactivity directed against IgE and/or FcERI $\alpha$. Since anti-IgE autoantibodies have been described in CU and have been implicated as a trigger mechanism of this disease, we decided to investigate the prevalence of the (co-)occurrence of anti-IgE and anti-FceRI $\alpha$ autoantibodies in $\mathrm{CU}$ patients. For the detection of anti-IgE Abs, monoclonal IgE anti-NP bound to immobilized BSA-NP was used as a target molecule. The specific IgG anti-IgE autoantibody-binding to membranes was visualized with an anti-human IgG reagent (Fig. 4, representative experi- 


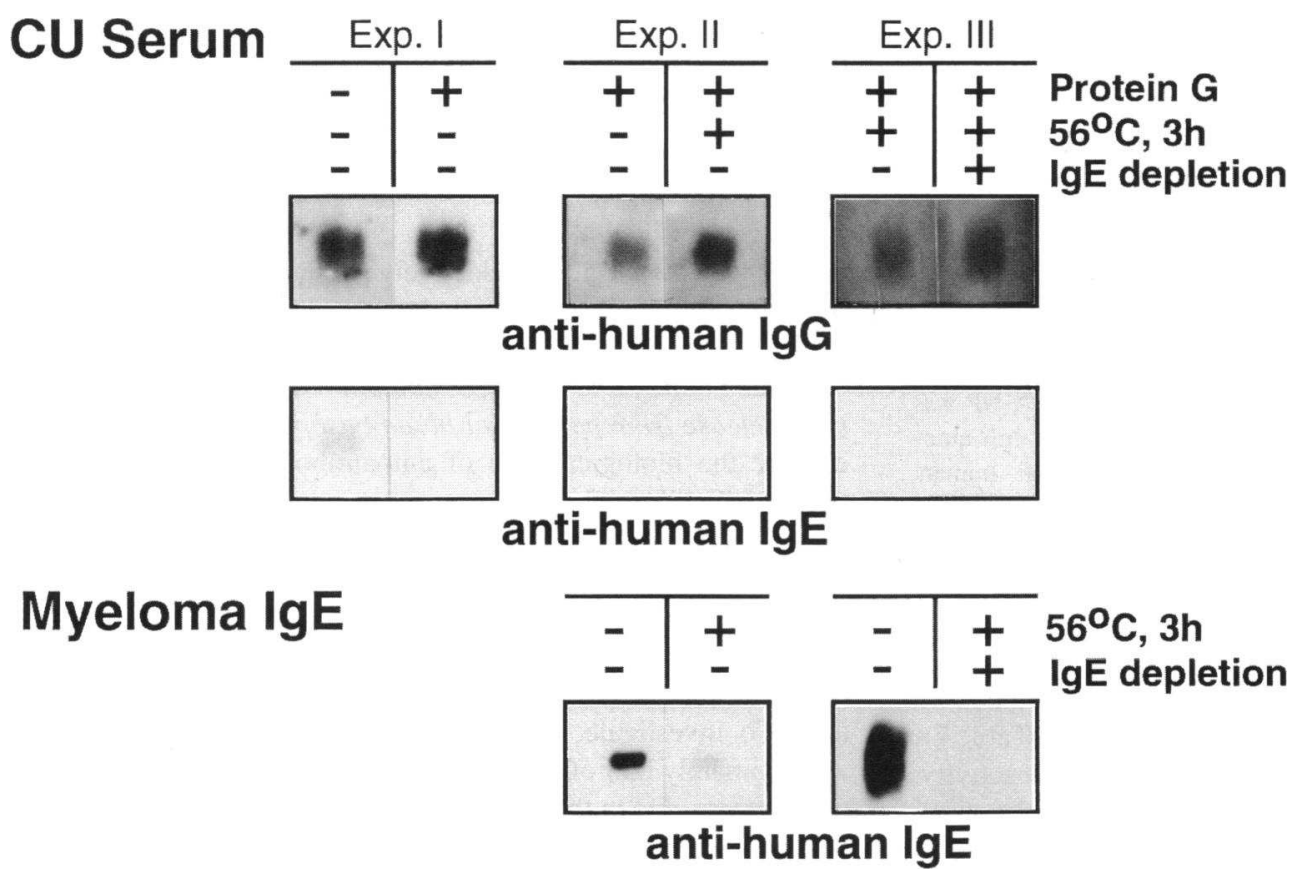

Figure 2. Elimination of residual IgE from CU-IgG isolates does not affect IgG-mediated antiFc $\varepsilon$ RI $\alpha$ immunoreactivity. In three independent experiments, the effect ( $s$ ) of protein $\mathrm{G}$ fractionation of serum (Exp.I), heat denaturation of protein $\mathrm{G}$ fractions

(Exp. II), and anti-IgE immunoaffinity depletion of heated protein $\mathrm{G}$ fractions (Exp. III) on Ig-mediated $\mathrm{Fc} \varepsilon \mathrm{RI} \alpha$ reactivity was (were) investigated. Unfractionated serum (Exp. I) and protein $\mathrm{G}$ isolates either mock-treated (Exps. I and II ), or subjected to heat treatment $\left(56^{\circ} \mathrm{C}, 3 \mathrm{~h}\right)$ and/or anti-IgE immunoaffinity depletion (Exps. II and III) were allowed to react with immobilized FceRI $\alpha$.

Fc $\varepsilon$ RI $\alpha$-bound IgG and IgE were detected with anti-human IgG and anti-human IgE Abs, respectively. The efficacy of heat treatment and/or IgE depletion procedures to abolish IgE-binding to immobilized FceRI $\alpha$ is demonstrated using myeloma IgE (Exps. II and III). Representative experiment $(n=4)$. ment). For control purposes, the binding of cIgE to BSA-NP was detected with an anti-IgE reagent (Fig. 4). BSA-NP in the absence of IgE anti-NP was used to demonstrate the anti-IgE specificity of the observed serum IgG-binding (Fig. 4). The comparison of anti-FceRI $\alpha$ reactivity (Fig. $5 A$ ) with anti-IgE reactivity (Fig. $5 B$ ) revealed that both autoantibodies can, but do not necessarily, co-occur in CU sera.

In an extended patient study, we evaluated the prevalence
A
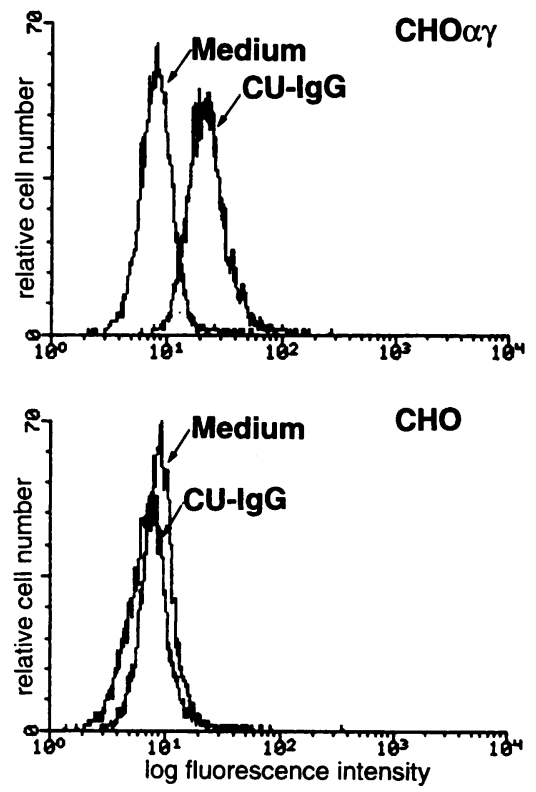

B

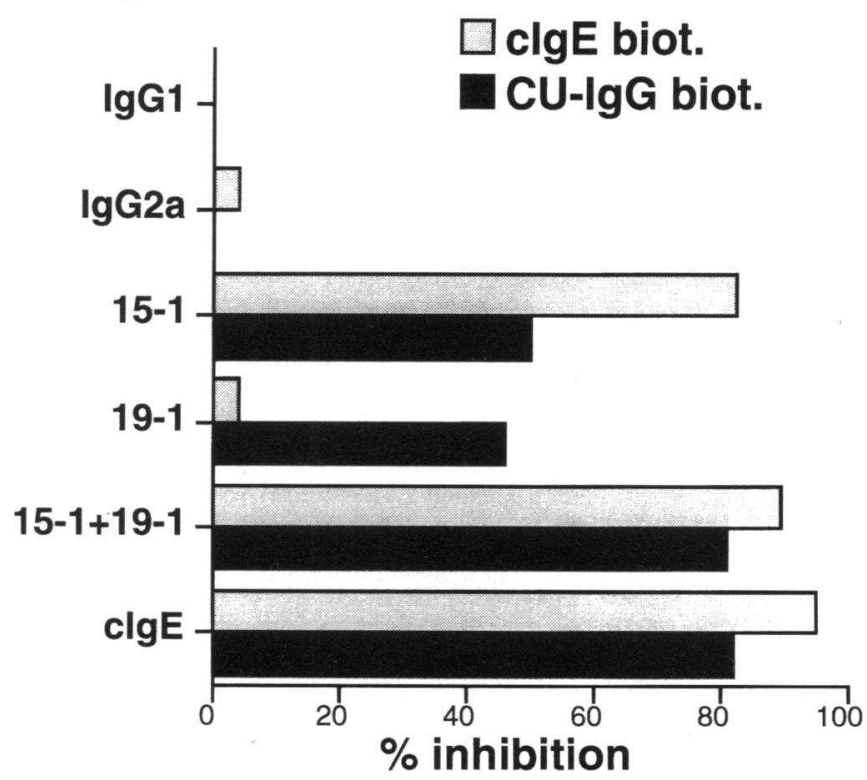

Figure 3. IgE-depleted CU-IgG binds to cell surface-expressed FceRI $\alpha$. (A) Binding of biotinylated CU-IgG to CHO $\alpha \gamma$ and to CHO cells was visualized by streptavidin-PE and analyzed by flow cytometry. Mean fluorescence intensity is given on the abscissa and the relative cell number on the ordinate. Representative experiment out of seven. $(B)$ Reactivity of biotinylated cIgE or biotinylated CU-IgG with CHO $\alpha \gamma$ cells after preincubation of the cells with mAbs 15-1, 19-1, 15-1 plus 19-1, cIgE, or IgG1 and IgG2a control mAbs. Abscissa shows the mAb-induced inhibition (\%) of cIgE- and CU-IgG-binding. 

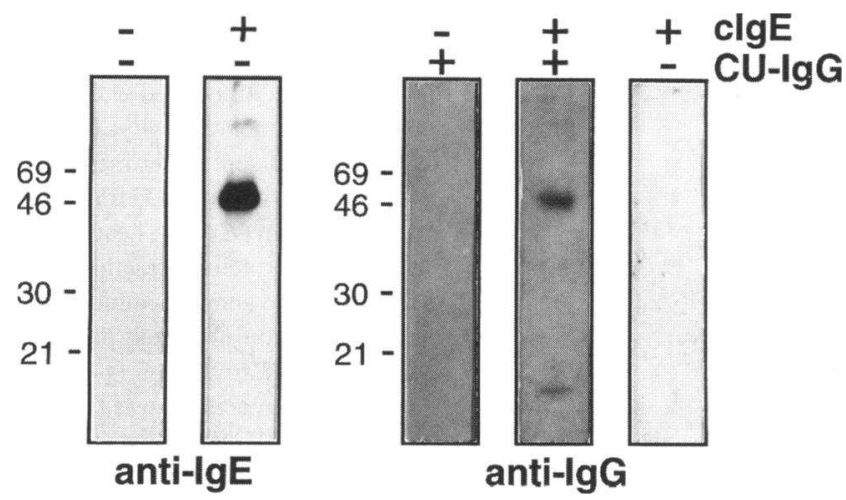

Figure 4. Biochemical demonstration of anti-IgE autoreactivity in CUIgG preparations. cIgE (IgE-anti NP)-binding to blotted BSA-NP was confirmed by anti-human IgE immunoreactivity (left). Anti-IgE autoantibodies in CU IgG fractions were detected with rabbit anti-human IgG Abs (right). Omission of either cIgE or CU-IgG results in loss of anti-human IgG reactivity. Molecular mass calibration is shown on the left in kilodaltons.

of anti-Fce RI $\alpha$ and anti-IgE autoreactivity in IgG fractions from $\mathrm{CU}$ patients, $\mathrm{AD}$ patients, and healthy controls (CO) (Table I). $37 \%$ of the CU-IgG samples exhibited anti-FceRI $\alpha$ reactivity, whereas none of the AD-IgG samples or IgG samples from healthy volunteers reacted. Anti-IgE reactivity was found in $69 \%$ of the CU patients, in $73 \%$ of AD-IgG samples, and in $26 \%$ of healthy controls. This observed prevalence of IgG antiIgE autoreactivity might even be underestimated because the experimental conditions used do not allow the detection of antiidiotypic or IgE-saturated IgG anti-IgE autoantibodies. IgG antiFceRI $\alpha$ and IgG anti-IgE autoreactivity co-occurred in $22 \%$ of the $\mathrm{CU}$ patients but in none of the AD patients or controls. Our data clearly show that, in contrast to anti-IgE autoreactivity,
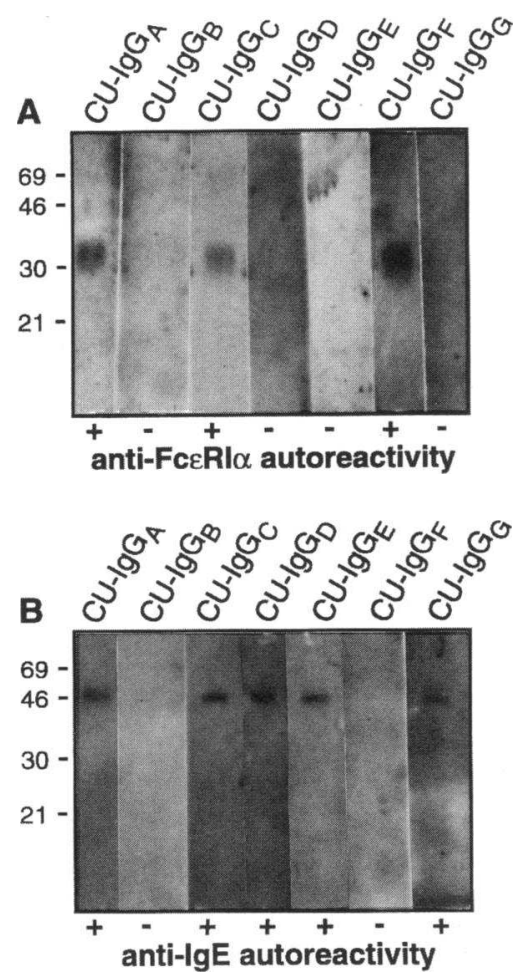

Figure 5. Comparative analysis of anti-FceRI $\alpha$ $(A)$ and anti-IgE $(B)$ autoreactivity in CU-IgG fractions. Sera of $\mathrm{CU}$ patients can contain IgG autoreactivity directed against either FceRI $\alpha$ $\left(\mathrm{CU}-\mathrm{IgG}_{\mathrm{F}}\right), \mathrm{IgE}(\mathrm{CU}-$ $\mathrm{IgG}_{\mathrm{D}}, \mathrm{CU}-\mathrm{IgG}_{\mathrm{E}}, \mathrm{CU}-$ $\left.\mathrm{IgG}_{\mathrm{G}}\right)$, or both $\mathrm{F} \varepsilon \varepsilon \mathrm{RI} \alpha$ and IgE $\left(\mathrm{CU}-\mathrm{IgG}_{\mathrm{A}}, \mathrm{CU}-\right.$ $\left.\mathrm{IgG}_{\mathrm{C}}\right)$. In one case $(\mathrm{CU}$ $\mathrm{IgG}_{\mathrm{B}}$ ) neither antigen is recognized. Molecular mass calibration is shown on the left in kilodaltons.
Table I. Patient Study

\begin{tabular}{llcr}
\hline & CU-IgG & AD-IgG & \multicolumn{1}{c}{ CO-IgG } \\
\hline Anti-Fc $\in$ RI $\alpha$ & $37 \%(12 / 32)$ & $0 \%(0 / 15)$ & $0 \%(0 / 15)$ \\
Anti-IgE & $69 \%(22 / 32)$ & $73 \%(11 / 15)$ & $26 \%(4 / 15)$ \\
Either/or & $81 \%(26 / 32)$ & $73 \%(11 / 15)$ & $26 \%(4 / 15)$ \\
Both & $22 \%(7 / 32)$ & $0 \%(0 / 15)$ & $0 \%(0 / 15)$
\end{tabular}

anti-Fc $\varepsilon \mathrm{RI} \alpha$ reactivity is selectively present in CU patients and - within this disease entity - defines a subgroup of such patients.

Anti-FceRI $\alpha$ and anti-IgE autoantibodies can induce histamine release from peripheral blood basophils. In an attempt to explore the biological role of autoantibodies against FceRI $\alpha$ and/or IgE, CU-IgG specimens were analyzed for their capacity to release histamine from basophils of healthy donors. Exposure to anti-FceRI $\alpha$ autoantibody-positive IgG fractions revealed a substantial release of endogenous histamine in four out of eight cases (Fig. 6, representative experiment, $n=3$ ). The magnitude of this response was comparable with positive control stimulation. To investigate whether the lack of mediator release in approximately half of the CU patients with anti-FceRI $\alpha$ autoantibodies was due to the receptor blockade by in vivo bound IgE, IgE was eluted from basophils by lactic acid stripping before exposure to IgG fractions. Neither the removal of surface-bound IgE (data not shown) nor the reconstitution of the stripped cells with $10 \mu \mathrm{g} / \mathrm{ml}$ monomeric IgE changed the histamine-releasing capacity of anti-FceRI $\alpha$-containing specimens (Fig. 6 A). Importantly, two of three anti-IgE-containing IgG fractions induced histamine release from basophils reconstituted with saturating doses of IgE (Fig. $6 \mathrm{~A}$, representative experiment, three independent experiments). To investigate whether the failure of certain FceRI $\alpha$-reactive IgG specimens to release histamine was due to low concentrations of autoantibodies present in these preparations, basophils were incubated with CU-IgG concentrations up to $5 \mathrm{mg} / \mathrm{ml}$ (dilution: 1:2). Fig. $6 B$ demonstrates that certain FceRI $\alpha$-reactive CU-IgG specimens, even when applied in high concentrations, did not result in induction of histamine release, whereas others activated basophils irrespective of the concentration used. Importantly, FceRI $\alpha$-nonreactive IgG from $\mathrm{CU}$ or $\mathrm{CO}$ did not induce histamine release at any of the concentrations tested (Fig. $6 B$ ). Although not all of the anti-FceRI $\alpha$ and/or anti-IgE autoantibody-containing $\operatorname{IgG}$ fractions were able to release histamine from peripheral blood basophils (Fig. $6, A$ and $B$ ), our data show that humoral autoimmune phenomena can be observed in the majority of $\mathrm{CU}$ patients and that, at least in a group of these patients, in vitro histamine release can be ascribed to the presence of autoantibodies.

\section{Discussion}

It is well known that serum of certain CU patients contains MC-activating properties as evidenced by its ability to elicit (a) localized urticarial skin reactions upon intradermal injection and $(b)$ histamine release from basophils in vitro $(8,9)$. IgG anti-IgE autoantibodies have been implicated as one of the factors responsible for this phenomenon. Due to their capacity to bind and, possibly, cross-link IgE molecules bound to FceRI on tissue MC, these autoantibodies may have the potential to induce histamine release in an IgE-dependent fashion. Indeed, 

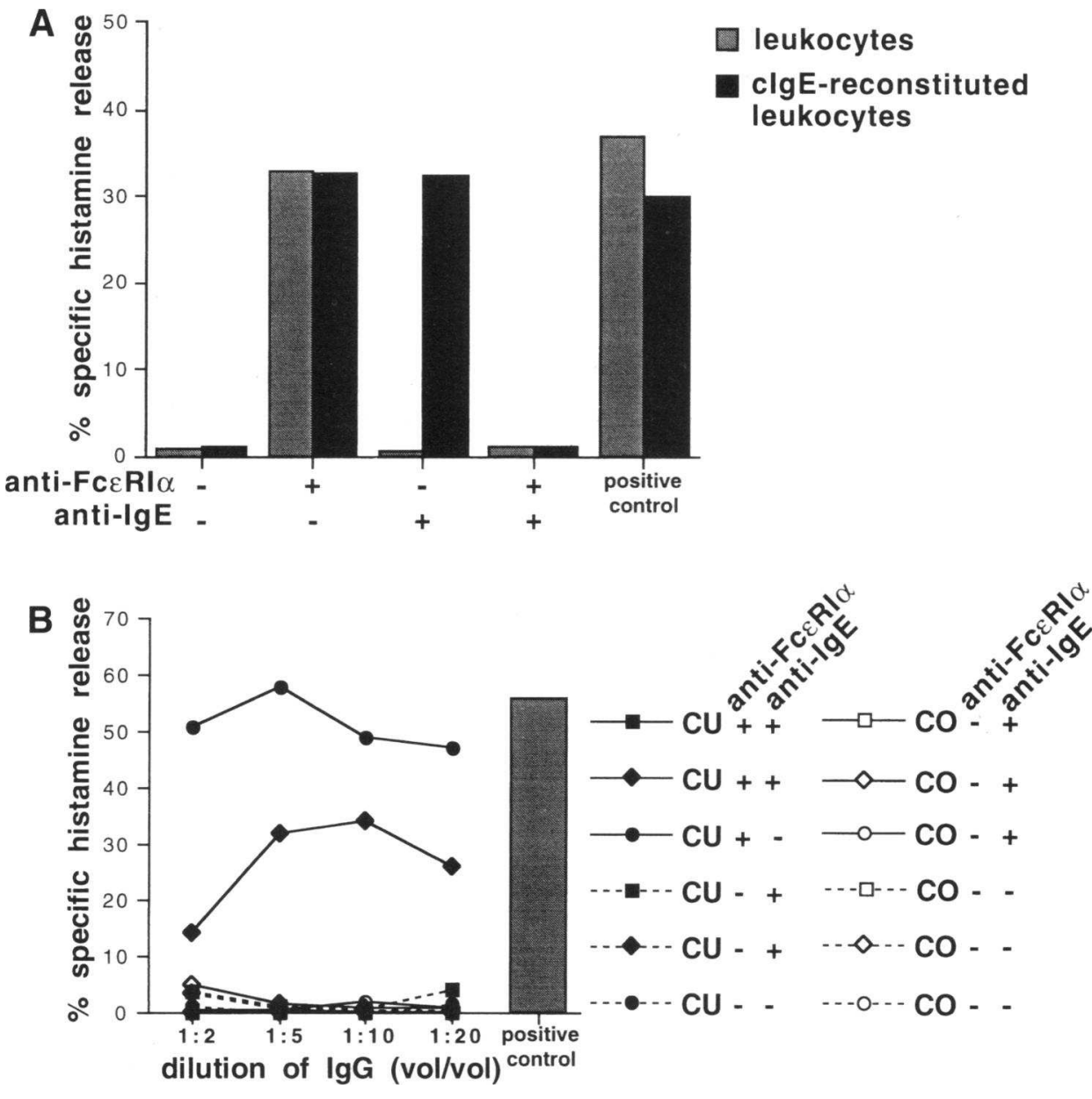

leukocytes

clgE-reconstituted leukocytes
Figure 6. (A) Both anti-FceRI $\alpha$-reactive and anti-IgE-reactive, IgE-depleted CU-IgG fractions can release histamine from peripheral blood basophils. Anti-FceRI $\alpha$-reactive and/or anti-IgE-reactive CU-IgG preparations were incubated for $40 \mathrm{~min}$ at $37^{\circ} \mathrm{C}$ with either untreated or IgE-exposed, basophil-enriched leukocytes before harvesting the supernatants.

$(B)$ The lack of histamine-releasing capacity of certain FceRI $\alpha$-reactive and of all nonreactive IgG samples is not reverted by increasing the concentration of IgG. For this purpose, basophil-enriched leukocytes were stripped and exposed to $1: 2,1: 5,1: 10$, or 1:20 diluted $\mathrm{CU}$ - or $\mathrm{CO}-\mathrm{IgG}$. As a positive stimulation control, cells were treated with a mouse anti-IgE mAb; histamine release in the presence of incubation buffer alone (negative control) was always $<5 \%$ of total cellular histamine. Specific histamine release $(\%)$ is given on the ordinate (total cellular histamine minus spontaneous release $=100 \%$ ). we (this study) and others (8) were able to show that exposure of IgE-bound basophils to IgG anti-IgE antibody containing IgG fractions from $\mathrm{CU}$ patients can, but does not necessarily, induce histamine release from these cells. Although detected in the serum of most $\mathrm{CU}$ patients (reference 7 and this study), IgG anti-IgE autoantibodies have also been found in sera of patients suffering from atopic dermatitis (references 21-23 and this study) and, even, of healthy individuals (reference 24 and this study). In atopic individuals, the analysis of epitopes recognized by IgG anti-IgE autoantibodies revealed that these antibodies recognize mainly idiotypic Fab rather than framework IgE heavy chain determinants (25). Therefore, they should have the potential to cross-link receptor-bound IgE rather than prevent Fc-IgE from binding to IgE receptors. Despite the presence of such autoantibodies, atopic patients - in contrast to $\mathrm{CU}$ patients - very rarely suffer from recurrent wheal-and-flare reactions in the absence of allergen. It is therefore quite unlikely that IgG anti-IgE autoantibodies play a major pathogenetic role in $\mathrm{CU}$.

Recent evidence points to the possibility that IgG autoreactivity directed against the $\alpha$ chain of the high affinity receptor for IgE can elicit clinical symptoms in CU (9). Although this study convincingly demonstrated IgG-mediated, Fc $\varepsilon$ RI $\alpha$-dependent histamine release from basophils, the experimental strategies used did not exclude the possibility that in vivo formed, protein $\mathrm{G}$-purified IgG/anti-IgE immune complexes were responsible for the observed phenomenon. Biochemical results obtained in our study definitively prove the existence of true IgG anti-FceRI $\alpha$ autoantibodies in CU sera by the demonstration that $(a)$ anti-Fc $\varepsilon \mathrm{RI} \alpha$-reactive serum antibodies were detected with anti-IgG but not anti-IgE reagents and that $(b)$ strategies resulting in complete elimination of IgE from CUIgG samples (anti-IgE immunoabsorbance and selective heat denaturation of IgE) did not decrease IgG-mediated antiFc $\varepsilon$ RI $\alpha$ immunoreactivity. The evaluation of the prevalence of anti-FceRI $\alpha$ autoantibodies in $\mathrm{CU}$ and $\mathrm{AD}$ versus $\mathrm{CO}$ revealed that - in contrast to the anti-IgE reactivity-IgE-independent Fc $\varepsilon R I \alpha$-specific autoreactivity resides selectively in the IgG fraction of $37 \%$ of $\mathrm{CU}$ patients but was not detected in either the $\mathrm{AD}$ or the $\mathrm{CO}$ group. The preferential, if not selective, occurrence of IgG anti-FceRI $\alpha$ autoantibodies in CU may not only constitute a discriminating disease marker but, further, may be of central pathophysiological relevance for the disease itself. To address this issue, we investigated the capacity of IgE-depleted anti-FceRI $\alpha$ autoantibodies containing IgG fractions to release histamine from peripheral blood basophils. $50 \%$ of these CU-IgG preparations were able to elicit responses that were shown to be IgE-independent since a similar histamine release was observed when IgE-saturated and IgE-eluted basophils were used. The fact that not all of the anti-FceRI $\alpha$-positive CU-IgG samples were able to release histamine in vitro suggests that factors other than the mere presence of the Abs, such as the affinity, epitope specificity, and/or IgG subtype composition of autoantibodies, may determine the outcome of the individual biological response. In particular, the subtype composition of autoantibodies is important for the quality and/or quantity of 
biological responses since IgG subtypes exhibit different capacities for complement fixation (26) and for binding to Fc $\gamma$ Rs (5). Putative complement fixing properties of these autoantibodies would explain why $\mathrm{MC}$ degranulation in $\mathrm{CU}$ is largely restricted to skin $\mathrm{MC}$ which - in contrast to lung $\mathrm{MC}$ - can be activated via the C5a receptor CD88 (27). It is tempting to speculate that autoantibodies incapable of inducing histamine release in vitro have MC-activating properties in the presence of complement in vivo. Finally, activation of $\mathrm{MC}$ in vivo may also be modulated by cross-linking of FceRI $\alpha$-bound IgG by anti-IgG autoantibodies, e.g., rheumatoid factors, by physical interaction with adjacent $\mathrm{Fc} \gamma \mathrm{R}$-bearing tissue-bound cells, or even by $\mathrm{Fc} \gamma \mathrm{Rs}$ expressed on the MC surface itself.

Our data demonstrate that anti-FceRI $\alpha$ autoantibodies occur preferentially, or perhaps even selectively, in CU patients and that, at least in certain incidences, these autoantibodies can induce histamine releases. The observation that anti-FceRI $\alpha$ antibodies apparently occur in a subset of CU patients only emphasizes the need for a reliable diagnostic screening system for this autoreactivity. The biochemical test system described in this study offers a routine diagnostic procedure for the detection of autoreactivity in CU sera and, therefore, allows the definition of an autoimmune-mediated subentity of this disease. Furthermore, these findings may form a basis for the development of new strategies for the treatment of CU. In this regard, the definition of non-IgE but autoantibody-binding peptides and their application in immunoaffinity-based selective elimination of FceRI $\alpha$-reactive autoantibodies may be a be a promising approach to the treatment of severe recalcitrant cases of $\mathrm{CU}$.

\section{Acknowledgments}

We wish to thank Friederike Pieczkowski for excellent technical assistance and Laura A. Stingl for critically reading the manuscript.

This work was supported, in part, by grants from the Austrian Science Foundation (S06702-MED) and from the Sandoz Research Institute.

\section{References}

1. Champion, R. H. 1990. A practical approach to urticarial syndromes-a dermatologist's view. Clin. Exp. Allergy. 20:221-224.

2. Kaplan, A. P. 1983. Chronic urticaria: possible causes, suggested treatment alternatives. Postgrad. Med. 74:209- 215, 218-222.

3. Schwartz, L. B. 1991. Mast cells and their role in urticaria. J. Am. Acad. Dermatol. 25:190-204.

4. Metzger, H. 1991. The high affinity receptor for IgE on mast cells. Clin. Exp. Allergy. 21:269-279.

5. Ravetch, J. V., and J.-P. Kinet. 1991. Fc receptors. Annu. Rev. Immunol. 9:457-492.

6. Grattan, C. E. H., D. M. Francis, N. G. P. Slater, R. J. Barlow, and M. W.
Greaves. 1992. Plasmapheresis for severe, unremitting, chronic urticaria. Lancet. 339:1078-1080.

7. Gruber, B. L., M. L. Baeza, M. J. Marchese, V. Agnello, and A. P. Kaplan. 1988. Prevalence and functional role of anti-IgE autoantibodies in urticarial syndromes. J. Invest. Dermatol. 90:213-217.

8. Grattan, C. E. H., D. M. Francis, M. Hide, and M. W. Greaves. 1991. Detection of circulating histamine releasing autoantibodies with functional properties of anti-IgE in chronic urticaria. Clin. Exp. Allergy. 21:695-704.

9. Hide, M., D. M. Francis, C. E. H. Grattan, J. Hakimi, J. P. Kochan, and M. W. Greaves. 1993. Autoantibodies against the high affinity IgE receptor as a cause of histamine release in chronic urticaria. N. Engl. J. Med. 328:1599-1604.

10. Inganas, M., S. G. O. Johansson, and H. Bennich. 1981. Anti-IgE antibodies in human serum: occurrence and specificity. Int. Arch. Allergy Appl. Immunol. 65:51-61.

11. Huston, D. P., and R. B. Bressler. 1992. Urticaria and angioedema. Med. Clin. North Am. 76:805-840.

12. Hanifin, J. M., and G. Rajka. 1980. Diagnostic features of atopic dermatitis. Acta Dermato-Venerol. 92:44-47.

13. Capron, A., J.-P. Dessaint, M. Capron, and H. Bazin. 1975. Specific IgE antibodies in immune adherence of normal macrophages to Schistosoma mansoni schistosomules. Nature (Lond.). 253:474-475.

14. Dorrington, K. J., and H. Bennich. 1973. Thermally induced structural changes in immunoglobulin E. J. Biol. Chem. 248:8378-8384.

15. Wang, B., A. Rieger, O. Kilgus, K. Ochiai, D. Maurer, D. Födinger, J.-P. Kinet, and G. Stingl. 1992. Epidermal Langerhans cells from normal human skin bind monomeric IgE via FceRI. J. Exp. Med. 175:1353-1365.

16. Shimizu, A., I. Tepler, P. N. Benfey, E. H. Berenstein, R. P. Siraganian, and $P$. Leder. 1988. Human and rat mast cell high-affinity immunoglobulin $E$ receptors: characterization of putative $\alpha$-chain gene products. Proc. Natl. Acad. Sci. USA. 85:1907-1911.

17. Maurer, D., C. Ebner, B. Reininger, E. Fiebiger, D. Kraft, J.-P. Kinet, and G. Stingl. 1995. The high affinity IgE receptor (FceRI) mediates IgE-dependent allergen presentation. J. Immunol. 155:6285-6290.

18. Maurer, D., E. Fiebiger, B. Reininger, B. Wolff-Winiski, M.-H. Jouvin, O. Kilgus, J.-P. Kinet, and G. Stingl. 1994. Expression of functional high affinity immunoglobulin E receptors (FcERI) on monocytes of atopic individuals. J. Exp. Med. 179:745-750.

19. Pruzansky, J. J., L. C. Grammer, R. Patterson, and M. Roberts. 1983. Dissociation of IgE from receptors on human basophils. I. Enhanced passive sensitization for histamine release. J. Immunol. 131:1949-1953.

20. Bischoff, S. C., T. Brunner, A. L. De Weck, and A. H. Dahinden. 1990. Interleukin 5 modifies histamine release and leukotriene generation by human basophils in response to diverse agonists. J. Exp. Med. 172:1577-1583.

21. Marone, G., V. Casoralo, R. Paganelli, and I. Quinti. 1989. IgG anti-IgE from atopic dermatitis induces mediator release from basophils and mast cells. $J$. Invest. Dermatol. 93:246-252.

22. Nawata, Y., T. Koike, H. Hosokawa, H. Tomoika, and S. Yoshida. 1985. Anti-IgE autoantibody in patients with atopic dermatitis. J. Immunol. 135:478482.

23. Quinti, I., C. Brozek, N. Wook, R. Geha, and D. Y. M. Leung. 1986. Circulating IgG autoantibodies to IgE in atopic syndromes. J. Allergy Clin. Immunol. 77:586-594.

24. Twena, D. M., J. S. Marshall, M. R. Haeney, and E. B. Bell. 1989. A survey of nonatopic and atopic children and adults for the presence of anti-IgE autoantibodies. Clin. Immunol. Immunopathol. 53:40-51.

25. Vogel, M., S. Miescher, C. Biaggi, and B. M. Stadler. 1994. Human antiIgE antibodies by repertoire cloning. Eur. J. Immunol. 24:1200-1207.

26. Tao, M. H., R. I. Smith, and S. L. Morrison. 1993. Structural features of human immunoglobulin $\mathbf{G}$ that determine isotype-specific differences in complement activation. J. Exp. Med. 178:661-667.

27. Füreder, W., H. Agis, M. Willheim, H. C. Bankl, U. Maier, K. Kishi, M. R. Müller, K. Cerwenka, T. Radaszkiewicz, J. H. Butterfield, et al. 1995. Differential expression of complement receptors on human basophils and mast cells. J. Immunol. In press. 